\title{
DEVELOPMENT AND SENSITIVITY ANALYSIS OF A TECHNICAL OBJECT INSPECTION MODEL BASED ON THE DELAY-TIME CONCEPT USE
}

\section{OPRACOWANIE I ANALIZA WRAŻLIWOŚCI MODELU KONTROLI STANU OBIEKTU TECHNICZNEGO Z WYKORZYSTANIEM KONCEPCJI OPÓŹNIEŃ CZASOWYCH*}

\begin{abstract}
In the presented paper, authors focus on the development of mathematical delay-time model for single-unit technical systems (technical objects) liable to costly failure. Failure is taken here to mean a breakdown or catastrophic event, after which the system is unusable until replacement. Implemented maintenance policy is the Block-Inspection Policy that assumes performing inspection actions at regular time intervals of $T$. In the perfect inspection case the availability and cost models are developed. This gives the possibility for analytical optimization of time between maintenance actions performance T for the infinite operational time of the system. Later, there is examined the compatibility of the developed analytical model with simulation results. The main target is to investigate what is the influence of the given model basic time components on the system availability ratio level and the system long-run expected maintenance costs. The analysis is conducted in the two main steps. The first one regards to analysis of expected number of events (failures, preventive replacements and inspection actions) in a single renewal cycle for the chosen range of time parameters: T and delay time $h$. In the next step, the availability ratio and long-run maintenance costs dependency on the chosen model's time parameters is under consideration. At the end, the directions for further research work are defined.
\end{abstract}

Keywords: delay time, block-based maintenance, inspection.

\begin{abstract}
$W$ artykule autorzy skupili się na opracowaniu matematycznego modelu utrzymania obiektów technicznych podlegających kosztownym uszkodzeniom z uwzględnieniem koncepcji opóźnień czasowych. Uszkodzenie w danym przypadku oznacza awarię lub zdarzenie katastrofalne, po którym obiekt jest niezdatny do użytku do momentu wymiany. Wykorzystano politykę blokowej kontroli stanu obiektu, która zakłada, że operacje diagnozy jego stanu sa przeprowadzane w regularnych odstępach co T jednostek czasu. Rozpatrzono model kosztowy oraz model gotowości dla przypadku perfekcyjnej diagnozy stanu obiektu. Pozwolito to na przeprowadzenie analitycznej optymalizacji okresu T między kolejnymi diagnozami stanu obiektu dla nieskończonego horyzontu czasowego. Następnie, zbadano zgodność opracowanego modelu analitycznego z wynikami uzyskanymi w drodze symulacji. Gtównym celem byto zbadanie wptywu podstawowych parametrów czasowych opracowanego modelu na poziom wspótczynnika gotowości oraz oczekiwanych kosztów utrzymania badanego obiektu. Analiza została przeprowadzona w dwóch etapach. Pierwszy obejmuje analize oczekiwanej liczby zdarzeń (uszkodzeń, wymian profilaktycznych oraz operacji kontroli stanu obiektu) dla wybranych zakresów parametrów czasowych: T $i$ opóźnienia czasowego $h$. W kolejnym kroku zbadano zależność wskaźnika gotowości $i$ oczekiwanych kosztów utrzymania obiektu od wybranych parametrów czasowych modelu. Pracę kończy wskazanie kierunków dalszych prac badawczych.
\end{abstract}

Stowa kluczowe: opóźnienie czasowe, obstugi blokowe, diagnozowanie stanu obiektu.

\section{Introduction}

Most of the technical systems are prone to the negative consequences associated with occurrence of unexpected failures due to e.g. degradation processes, environmental conditions, or operator decisions (e.g. [2, 3, 21, 31, 42]). For example, the wear processes are the most common cause of damage (about $70-80 \%$ of all the occurred failures) in mechanical devices [22, 41]. Following this, in order to prevent those negative consequences there are introduced some preventive actions related to technical systems maintenance issues.

The tasks connected with appropriate maintenance strategy selection and its parameters optimization are very challenging ones due to the necessity of taking into account a number of requirements connected with processes randomness, limited resources which support operational processes performance, and complexity of analysed tech- nical systems $[28,33]$. That is why, over the last 40 years there can be observed an increased interest in problems of technical systems and objects maintenance modelling processes that include e.g. preventive replacement scheduling tasks, inspection policy implementation, or corrective maintenance performance $[32,34]$. In particular the pioneering research works dedicated to the maintenance modelling issues especially investigate the performance of single-unit systems (see e.g. works $[17,30,35])$. One of the main research tasks in this area is the optimization of time period between inspection actions performance (e.g. [18]), which is also under authors investigation in this paper.

The authors focus on the modelling of inspection maintenance policy for technical systems/objects based on the technique called a delay time concept (DT). This maintenance approach was developed by Christer et al. (see e.g. [9, 10, 12, 13]). Similarly to Reliability Centred Maintenance strategy (RCM) [20], the delay-time concept is

(*) Tekst artykułu w polskiej wersji językowej dostępny w elektronicznym wydaniu kwartalnika na stronie www.ein.org.pl 
based on a division of technical object's degradation process into two main phases: normal operation (object fully up-stated) and phase of the work, where there can be observed some symptoms of forthcoming failure of components or a system (object partially up-stated). The time period of the second phase is called the delay time, and denoted by $h$ [7]. The known models that base on the implementation of delaytime concept are mainly used for optimizing the time periods between system/object inspection action performances in order to detect some potential signs of future possible failure occurrence. In the case of identification of such symptoms, the technical object is preventively repaired or replaced, which allows for improvement of system dependability characteristics and system total maintenance costs reduction [36]. Recent literature reviews, in which delay-time models are investigated along with other preventive maintenance models, are given in e.g. $[16,23,26,30]$. Recent state of art works, dedicated strictly to delay-time modelling are given in e.g. [7, 8, 36, 37].

In the area of maintenance modelling of single-unit systems with the use of delay-time approach, one of the first developed works is [13]. Authors in this work investigate a model of equipment-replacement decision process based upon a survey of maintenance managers. The survey research was done in order to investigate how replacement decisions are made in practice. The research study involved the surveys of 19 employees of various organizations. The main focus was to define the criteria which have the biggest influence on maintenance decisions.

Later, in [4], there is analysed the repairable machine that may fail or suffer breakdown many times during the course of its service lifetime, and is inspected for visible faults at intervals. The authors mostly focus on the problem of model parameter estimation with the use of maximum likelihood method and Akaike Information Criterion, providing also a model for imperfect inspections performance.

In work [5] authors develop a two-phase inspection policy model for a single component protection or preparedness system, in which the component arises from a heterogeneous population. The analysed system is required only in an emergency (system on-demand). The modelled two-phase inspection policy bases on the implementation of two inspection frequencies - an anticipated high inspection frequency in early life and low inspection frequency in later life. The optimization process is considered using availability and cost criteria. The policy is investigated in the context of a valve in a natural gas supply network.

Another interesting maintenance model of single-unit system with the use of delay-time approach is presented in work [20]. In the presented paper, author considers a problem of optimal inspection interval determination based on the timeliness measure introduction. The defined measure reflects the expected time between the last inspection and the item failure. Moreover, its minimum defines the optimal inspection interval that can be obtained using Monte Carlo simulation approach.

Moreover, there are also developed in the literature the maintenance models for technical objects that introduce a novel assumption - the so-called postponed replacement. An example here may be the work [33], where authors propose a new delay time model that allows replacement of object with detected defect to be postponed for an additional time period. The key motivation is to achieve better utilization of the system's useful life, and reduce replacement costs by providing a sufficient time window to prepare maintenance resources. The model is analysed for the cases when the delay time is a deterministic and random variable.

Delay time models of single-unit systems reliability are developed in $[1,6,11,19,43]$. In [11], author presents simple reliability model of a single component subject to one type of inspect able defect, when inspections are assumed to be perfect. Author focuses on the analysis of the influence of the length of time between inspection actions performance on system reliability characteristics. Then the model is generalized by introducing the possibility of the appearance of the different types of defects (occurring independently in the system). This problem is later investigated in [6], where author simplifies the developed model and provides some numerical examples. The same model given in [11] is provided in [1], when delay time and time to failure densities are exponentially distributed. Later, in [19], authors extend a delay time model with periodic testing process by developing availability function in accordance with the length of time between inspection actions performance. Authors analyse three different variants of the model: the case with no mechanical possibility to detect a defect, zero delay time occurrence, or no inspection actions performance during maintenance processes of the investigated technical object. In the next work, [43], authors investigate the model to evaluate the reliability and optimise the inspection schedule for a multi-defect component. There is also considered the situation of non-constant inspection intervals.

The developed delay-time based maintenance models for singleunit systems under condition based maintenance are presented e.g. in works $[14,24,25]$. In [14], authors analyse an inspection modelling problem for a production plant under condition monitoring. In the analysed article a condition monitoring test checks the state of wear of a component and records a $(0,1)$ signal depending upon all being well or that wear is below a critical level with the possibility of imminent failure. Following this, in the optimization model the decision variables are the critical warning level and frequency of monitoring inspections. Later, in works $[24,25]$, authors develop a method for determining the discrete time points of inspection for a deteriorating single-unit system under condition-based maintenance. The delaytime model is here utilized to describe the transition of the system's states. Moreover, two types of probabilities with respect to inspections are considered - a failed-dangerous probability of type I error, and a failed-safe probability of type II error.

In the known literature, there can be also found some models dedicated to single-component systems' risk analysis of maintenance activities performance (see e.g. [38]), semi-Markov processes implementation (see e.g. [15]), or safety inspection processes optimization (see e.g. [39]). The example of delay time model for a single unit case is given in [40], where authors propose a method to find costoptimized maintenance of an elevator.

The previously presented in the literature delay-time-based maintenance cost and availability models were mainly limited to the analysis of the first inspection period (the time between the moment of the "as good as new" technical object performance beginning to the moment of its first inspection action performance). In practice, this would mean the definition of the time of the first inspection action performance and the lack of guidelines for further maintenance procedures performance in the case of not detecting of symptoms of forthcoming failure (e.g. DT models presented in [27]). The use of Block inspection policy in real-life operating systems involves periodic inspection actions performance. This makes that it is necessary to determine the time period between inspection actions performance that is the best from the point of view of maintenance costs minimizing in the long run.

Therefore, the article focuses on the development of a mathematical model for a technical object maintenance, which extends the approach used so far and allows analysing the long-term operation time period of a single-unit system. The model gives the possibility to find a constant time period between the inspection actions performance that is optimal due to minimal maintenance costs or maximal availability criterion satisfaction. Depending on the inspection action results, there are taken necessary actions (maintenance and/or further operation). The next inspection is performed after the next time period $T$ regardless of the earlier inspection results. This significantly simplifies the management process of technical object maintenance. 
Moreover, there is presented an analysis of the sensitivity of the developed model to the selected parameters that gives the possibility to indicate certain relationships, which can facilitate the search for the optimal period between inspection actions performance due to the both considered criteria.

As a result, in the next Section there are presented the modelling problem description and main assumptions. This gives the possibility for the investigation of the mathematical maintenance model for technical unit that base on Block Inspection policy implementation. The optimization criteria include the long-run expected maintenance costs and availability ratio for the given technical object. Later, there is examined the compatibility of the developed analytical model with simulation results. Then there is conducted the sensitivity analysis and later there is analysed the possibility of using the presented maintenance model to optimize the technical object's inspection period. The work ends with a summary.

\section{Problem description and main assumptions}

\subsection{Problem description}

In the presented paper, there is analysed a technical object with time delay, subject to periodic inspection maintenance. The conducted research study focuses on objects that are unrepairable or repairable but their corrective maintenance performance is costly ineffective. At the same time, it is assumed that the technical object has a single failure mode, and symptoms of forthcoming failure are identifiable during inspection actions performance.

Based on the relevant scientific literature, here we analyse a singleunit system subject to periodic inspection. An implemented maintenance policy is the Block Inspection policy. This maintenance policy assumes that the performed inspections are carried out in order to check the working status of the object and take place at regular time intervals of $T$. The purpose of such inspection action is to establish if the technical object is still operable. Due to the simplicity of this type of maintenance policy, it is still often recommended by manufacturers. An example of this type of maintenance policy may regard to the periodic inspections of hydraulic pressure in e.g. wheel loaders. Such break pressure checking is performed in every 1000 machine working hours.

Moreover, the inspections of technical object are assumed to be perfect. In the presented article the inspections are assumed to be perfect. As a result, object defect, which occurs till the moment of inspection, will be identified and replaced within the inspection period. At the same time, it is assumed that if these symptoms are diagnosed, the object will be replaced by a new one. Moreover, failure is observed immediately and the object is replaced at a given cost and downtime. The main decision variable in the model is the inspection interval $T$, which is called the maintenance cycle. The objective of the model is to define and estimate the availability ratio of the object and the long-term expected maintenance costs for a single renew period for the case of the random nature of the exploitation process (random moments of defects and failure occurrence). For the modelling purpose, we propose the following additional assumptions.

\subsection{Assumptions}

In the presented work, the general assumptions we make to characterize the operation and maintenance of the non-repairable technical unit are listed below:

1) the technical object is a three state object where, over its service life, it can be:

- operating - able to fulfil the operational tasks and functions (later called as full up-state),

- partially operating (denoting the existence of a defect in the object that is defined as the occurrence of the symptoms of potential failure - in the further part of the study called as incomplete or partial up-state), or
- down for necessary repair (after the technical object failure occurrence, defined as the loss of the ability of the object to perform the required functions),

2) the object is renewed (replaced by a new one that has identical reliability characteristic) at either a failure repair or at a repair done at an inspection if a defect is identified,

3) failures of the object are identified immediately,

4) replacements are made as soon as possible and have a constant time. The time required for the object replacement is determined by variables $d_{f}$ and $d_{r}$ in Subsection 3.1.,

5) the object inspection action lasts a constant time (determined by a variable $d_{i n}$ described in Subsection 3.1.) and begins the new inspection cycle $T$ for the analysed object (presented graphically in the Fig. 2).

\section{Inspection model for a single-unit system based on the delay-time concept implementation}

Here authors investigate a case of a technical object performing under Block Inspection policy principles. In general, the analysed object may be in one of the three maintenance operations: failure repair without additional inspection action performance, planned inspection performance with replacement of an element if a defect is detected, or planned inspection action performance without replacement of an element (defect not detected, object assumed to be fully up-stated). Thus, if the inspection action reveals a failure or a defective state of the object, a repair or replacement is initiated immediately otherwise it remains in service.

For the needs of this research, the period between the moment of the new technical object operation beginning to the moment of its replacement is called the "renewal cycle", while the time elapsing between two successive inspections (or inspection and successive system failure) is called the "inspection cycle". Figure 1 illustrates the definition of the initial and delay times in the case of one component maintenance. Figures 2 and 3 present the renewal and defect renewal cycle for a technical objects.

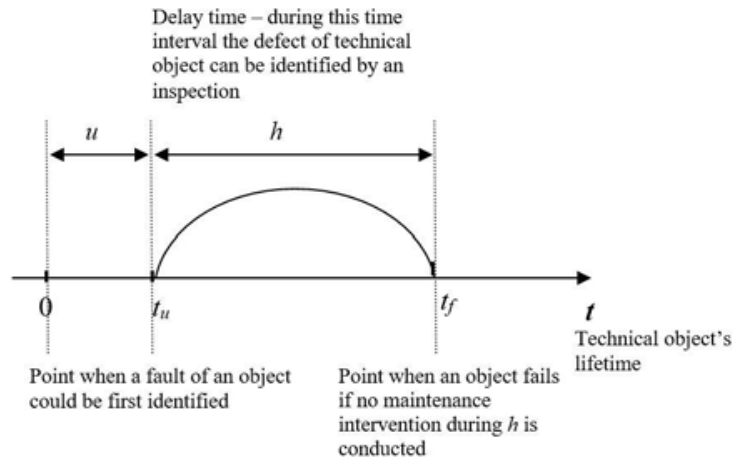

Fig. 1. The initial and delay times of a single-unit technical system failure process. Source: Own contribution based on [8]

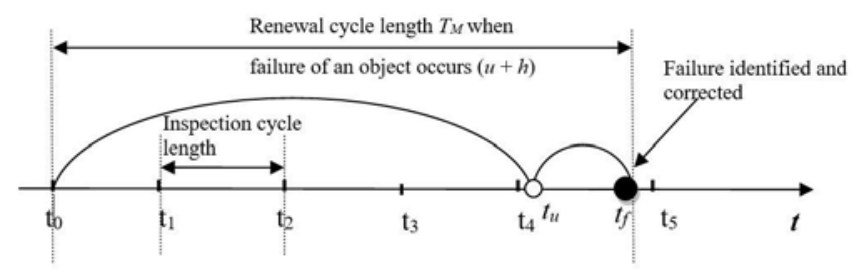

Fig. 2. Failure renewal cycle length of an analysed single-unit technical system

For the presented model assumptions, there can be estimated the availability ratio and the long-term maintenance costs for a given re- 


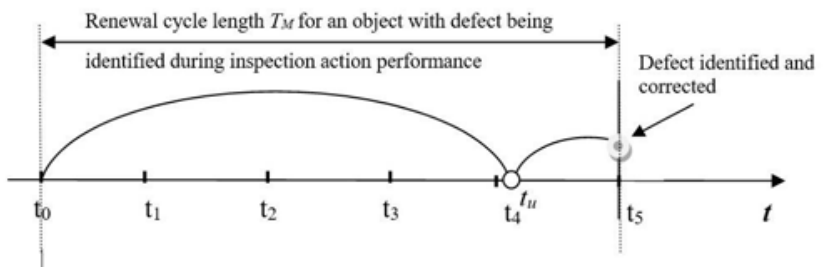

Fig. 3. Defect renewal cycle length of an analysed single-unit technical system

newal cycle (composed of inspection cycles of length $T$ ), giving a foundation to look for the best value of the $T$ period. In order to determine these characteristics, the modelling efforts will be subjected to analysis of one renewal cycle of a technical object. In practice, this approach makes it possible to estimate the costs and the availability of the object in an infinite horizon time period, because the determined probabilities and expected values will be the same for subsequent renewal cycles. This is due to the fact that after the end of the analysed/ modelled renewal cycle, the object is replaced (preventively or correctively) with a new one with identical reliability characteristics.

The availability and cost results need to estimate the probabilities of the object being in the possible reliability states in a single renewal period, like object uptime, object partially uptime (there are signs of forthcoming failure) and system downtime (failure) in the long term (when $t \rightarrow \infty$ ). Determination of these probabilities, taking into account the fact of the object inspection performance, gives the possibility in the next step to estimate the expected values of its maintenance costs and its reliability characteristics.

\subsection{Notation}

In order to develop an analytical delay-time model we shall adopt the following notation:

$h$

the delay time of the defect, denoting the period between the moment of appearance of the first symptoms of the potential failure and the moment of the object failure occurrence

$u \quad$ initial time of the defect

$t_{u} \quad$ the moment of the first symptoms of the potential failure occurrence

$t_{f} \quad$ the random moment of failure occurrence in the object

$t_{i} \quad$ the moment of the $i$ th inspection action performance, where $i=1,2,3, \ldots, \infty$

$t_{i} \rightarrow \infty \quad$ the moment of the $i$ th inspection action performance for $i \rightarrow \infty$ (infinite horizon time)

$T_{i} \quad$ time of $i$ th inspection cycle performance (between two consecutive inspection actions performance)

$F(t) \quad$ Cumulative distribution function of an object's time to failure $t$

$f_{h}(h) \quad$ Probability density function of the delay time $h$

$F_{h}(h) \quad$ Cumulative distribution function of the delay time $h$

$g(u) \quad$ Probability density function of the initial time $u$, which elapses from the beginning of operation by an "as good as new" object until the moment of first symptoms of failure occurrence

$G(u) \quad$ Cumulative distribution function of the initial time $u$, which elapses from the beginning of operation by an "as good as new" object until the moment of first symptoms of failure occurrence

$R(t) \quad$ Reliability function of an object being operated by time $t$

$P_{I}\left(t_{i}\right) \quad$ probability that during the $i$ th inspection action performance, an object is still up stated

$L_{I}(t i \rightarrow \infty) \quad$ the expected number of inspection actions performance in a single renewal cycle of an object, during which it will be up stated
$P_{R}(t i \rightarrow \infty) \quad$ the probability that an object will be replaced during a single renewal cycle

$P_{F}(t i \rightarrow \infty) \quad$ the probability of corrective replacement of an object in a single renewal cycle

$L_{R}(t i \rightarrow \infty) \quad$ the expected number of preventive replacements performance in a single renewal cycle

$L_{F}(t i \rightarrow \infty) \quad$ the expected number of an object failures occurrence in a single renewal cycle

$T_{M}\left(t_{1}\right) \quad$ the expected lifetime of an object (up state and partially up state time periods) in the first inspection cycle

$T_{M}\left(t_{i} \rightarrow \infty\right)$ the expected lifetime of an object (up state and partially up state time periods) from the moment of its operation beginning to the moment of its replacement (the length of a renewal cycle according to the Fig. 2 and 3)

$R_{h}\left(t_{1}, t_{2}\right) \quad$ the probability that in the time period between time moments $t_{1}, t_{2}$ the symptoms of forthcoming failure will occur, but an object will not fail up till the time moment $t_{2}$

$T_{I}\left(t_{i} \rightarrow \infty\right) \quad$ the expected time of inspections carried out in an object during a single renew period

$d_{\text {in }} \quad$ single inspection action performance time

$T_{R}\left(t_{i} \rightarrow \infty\right) \quad$ the expected preventive replacement time of an object during a single renew period

$d_{r} \quad$ object's defect replacement time

$T_{F}\left(t_{i} \rightarrow \infty\right)$ the expected failure replacement time of an object during a single renew period

$d_{f} \quad$ object's corrective replacement time (after failure occurrence)

$A\left(t_{i} \rightarrow \infty\right) \quad$ the availability ratio of an object for a single renew period

$C_{I}\left(t_{i} \rightarrow \infty\right) \quad$ the expected cost of inspection action performance per a single renewal cycle

$c_{i n} \quad$ unit inspection cost of an object

$C_{R}\left(t_{i} \rightarrow \infty\right) \quad$ the expected cost of preventive replacement performance in a single renewal cycle

$c_{r} \quad$ unit replacement cost of an object

$C_{F}\left(t_{i} \rightarrow \infty\right)$ the expected cost of corrective replacement performance in a single renewal cycle

$c_{f} \quad$ unit consequence costs incurred in the case of object

$C\left(t_{i} \rightarrow \infty\right)$ failure

time

\subsection{Probabilities of a system uptime, partially uptime and failure in a single renewal cycle}

Assuming that the failure of the object is always preceded by detectable symptoms, there is a possibility to define the Cumulative distribution function of time to failure, $F(t)$, as the convolution of $u$ and $h$ such that $u+h \leq t[27]$ :

$$
F(t)=\int_{u=0}^{t} g(u) F_{h}(t-u) d u
$$

And the reliability: $R(x)=1-\mathrm{F}(x)$

The probability $P_{I}\left(t_{i}\right)$ that during the $i$ th inspection action performance of the technical object (which started working as a "new" one) it will still be in the up state, can be defined as:

$$
P_{I}\left(t_{i}\right)=\left(1-G\left(t_{i}\right)\right)=1-\int_{0}^{t_{i}} g(u) d u, \text { where: } t_{i}=T, 2 T, 3 T, \ldots, i T(2)
$$


Based on this, it is possible to determine the expected number of inspection actions performance in a single renewal cycle, during which the object will be up-stated $L_{I}\left(t_{i} \rightarrow \infty\right)$ :

$$
L_{I}\left(t_{i} \rightarrow \infty\right)=\sum_{\mathrm{i}=1}^{\infty}\left(P_{I}\left(t_{i}\right)\right)=\sum_{\mathrm{i}=1}^{\infty}\left(1-G\left(t_{i}\right)\right)=\sum_{\mathrm{i}=1}^{\infty}\left[1-\int_{0}^{t_{i}} g(u) d u\right]
$$

The second possible situation that can occur during the object inspection action performance regards to the necessity of its replacement due to existing signals of the potential forthcoming failure. In order to illustrate the possibility of preventive replacement occurrence during the modelled (single) renewal cycle, the Figure 4 shows alternative possibilities of the occurrence of a sequence of events that cause the preventive replacement maintenance during the first three inspection cvcles. carried out within one renewal cvcle.

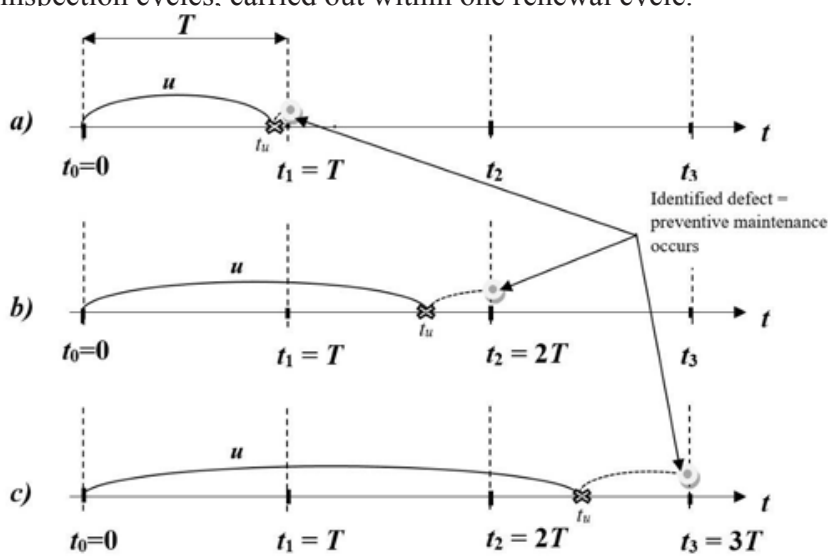

Fig. 4. Scheme for the renewal cycle length, when the symptom of potential system's failure (defect) is identified during inspection action performance in the first (a), second (b) and third (c) inspection cycle

Figure 4 shows the examples of the versions of the random time period durations: up to the occurrence of defect $(u)$ and the delay time $(h)$, which would result in the preventive replacement performance at the time $T$ (Fig. 4a), at the time $2 T$ (Fig. 4b), or at the $3 T$ (Fig. $4 \mathrm{c})$. The probability of each of the variants occurrence (a, b, c) may be determined for one inspection cycle. For example, for the second inspection cycle (Fig. 4b), the probability that symptoms appear during his lifetime, and the object will be preventively replaced at the time $2 T$ can be described as:

$$
P_{R}\left(t_{i}=2 T\right)=\int_{t_{1}}^{t_{2}} g(u)\left(1-F_{h}\left(t_{2}-u\right)\right) d u
$$

Based on this, there is possible to estimate the probability of the object preventive replacement in the infinite renewal cycle. The probability $P_{R}\left(t_{i} \rightarrow \infty\right)$ that an item should be replaced preventively can be described as the sum of the probabilities that during subsequent inspection actions performance there will be observed symptoms of future possible failure occurrence:

$$
P_{R}\left(t_{i} \rightarrow \infty\right)=\sum_{\mathrm{i}=1}^{\infty}\left(R_{h}\left(t_{i-1}, t_{i}\right)\right)=\sum_{\mathrm{i}=1}^{\infty}\left[\int_{t_{i-1}}^{t_{i}} g(u)\left(1-F_{h}\left(t_{i}-u\right)\right) d u\right]
$$

Due to the fact that preventive replacement is univocal to the end of the analysed renewal cycle, the series given by the equation (5) converges to an asymptotic value describing the probability of preventive replacement performance during one inspection cycle.

The estimation of cost and reliability characteristics of the analysed object also needs to determine the possibility of its failure. The probability that the object will fail during the inspection cycle depends on whether there will be visible symptoms of forthcoming failure and failure occurs before the next inspection action performance. As in the case of preventive replacement, the probability of the technical object failure is calculated for successive periods of maintenance, carried out within one renewal cycle, which ends with the corrective replacement action performance. Examples of possibilities of the failure occurrence during $t=\left(0, t_{3}\right)$ are shown in the Figure 5 .

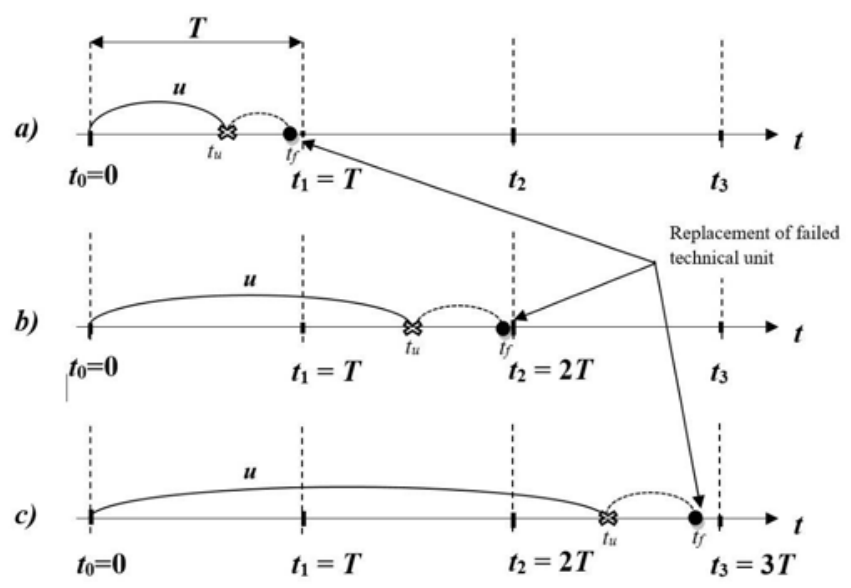

Fig. 5. Scheme for the renewal cycle length, when system's failure occurs in the first (a), second (b) and third (c) inspection cycle

The probability of corrective replacement of the object in a single renewal cycle may be estimated by:

$$
P_{F}\left(t_{i} \rightarrow \infty\right)=\sum_{i=1}^{\infty}\left[\int_{t_{i-1}}^{t_{i}} g(u)\left(F_{h}\left(t_{i}-u\right)\right) d u\right]
$$

The variables $P_{R}\left(t_{i} \rightarrow \infty\right)$ and $P_{F}\left(t_{i} \rightarrow \infty\right)$ represent the probabilities of preventive and corrective replacement necessity in the object as well as they express the expected number of possible preventive and corrective replacements in a single renewal cycle of the object. This is connected with the adopted assumption that during the whole renewal cycle there is possible only one replacement of the object, which determines the moment of renewal cycle end:

$$
\begin{aligned}
& L_{R}\left(t_{i} \rightarrow \infty\right)=1^{*} P_{R}\left(t_{i} \rightarrow \infty\right) \\
& L_{F}\left(t_{i} \rightarrow \infty\right)=1^{*} P_{F}\left(t_{i} \rightarrow \infty\right)
\end{aligned}
$$

\subsection{Availability ratio for a system}

In the curse of the first inspection cycle the expected lifetime of the object may be expressed as:

$$
T_{M}\left(t_{1}\right)=\int_{0}^{t_{1}} x \int_{0}^{\mathrm{x}} g(u) f_{h}(x-u) d u d x+\mathrm{t}_{1} \cdot \int_{u=0}^{t_{1}} g(u)\left(1-F_{h}\left(t_{1}-u\right)\right) d u
$$

The first component of the sum in the formulae (9) expresses possible moments of object failures, while the second part of the expression takes into consideration the probability that the object defect is 
observed in the time of the first inspection performance (then there is a necessity to replace it preventively).

The total expected length of the object up time in the curse of a single renewal cycle may be estimated as the sum of expected lifetimes resulting from the sequence of inspection periods, when $t_{i} \rightarrow \infty$ :

$$
T_{M}\left(t_{1}\right)=\int_{0}^{t_{1}} x \int_{0}^{\mathrm{x}} g(u) f_{h}(x-u) d u d x+\mathrm{t}_{1} \cdot \int_{u=0}^{t_{1}} g(u)\left(1-F_{h}\left(t_{1}-u\right)\right) d u
$$

In order to estimate the expected length of the object renewal time period there should be determined the expected times of all maintenance operations being performed in a single renewal cycle.

The next inspection ( $i$ th) may be taken depending on the probability of the two facts: that a previous inspection has not revealed defect occurrence and at the end of $(i-1)$ th inspection period the object is still reliable. Following this, the expected time of inspections carried out in the object during a single renew period takes into account the probabilities $P_{R}\left(t_{i} \rightarrow \infty\right)$ and $P_{F}\left(t_{i} \rightarrow \infty\right)$. Thus, when one wants to estimate the expected time of inspection actions performance in a single renew cycle, the formulae (11) may be applied:

$$
T_{I}\left(t_{i} \rightarrow \infty\right)=d_{\text {in }} \cdot\left(L_{I}\left(t_{i} \rightarrow \infty\right)+L_{R}\left(t_{i} \rightarrow \infty\right)\right)
$$

The estimation of the expected time of preventive replacement of the technical object in the course of a single renew period should base on the probability of defect occurrence at the end of an inspection cycle and lack of this defect at the moment of the previous inspection performance:

$$
T_{R}\left(t_{i} \rightarrow \infty\right)=d_{r} \cdot L_{R}\left(t_{i} \rightarrow \infty\right)
$$

Moreover, there should be estimated the expected failure time in a single renew cycle. The time depends on the failure probability in a given inspection period, assuming that at the moment of a previous inspection performance any defect has not been detected:

$$
T_{F}\left(t_{i} \rightarrow \infty\right)=d_{f} \cdot L_{F}\left(t_{i} \rightarrow \infty\right)
$$

The calculated functions (10)-(13) allow estimating the availability ratio for the cycle $A\left(t_{i} \rightarrow \infty\right)$, according to the well-known formulae:

$$
\mathrm{A}\left(t_{i} \rightarrow \infty\right)=\frac{\mathrm{T}_{\mathrm{M}}\left(t_{i} \rightarrow \infty\right)}{\mathrm{T}_{\mathrm{M}}\left(t_{i} \rightarrow \infty\right)+\mathrm{T}_{\mathrm{I}}\left(t_{i} \rightarrow \infty\right)+\mathrm{T}_{\mathrm{F}}\left(t_{i} \rightarrow \infty\right)+\mathrm{T}_{\mathrm{R}}\left(t_{i} \rightarrow \infty\right)}
$$

\subsection{The long-run expected maintenance costs of a system}

The estimation of expected maintenance cost results of the object needs the definition of the basic cost components connected with inspection performance, preventive replacements and corrective replacement. For the single renewal cycle, these basic cost components may be estimated similarly as time characteristics:

$$
\begin{gathered}
C_{I}\left(t_{i} \rightarrow \infty\right)=c_{\text {in }} \cdot\left(L_{I}\left(t_{i} \rightarrow \infty\right)+L_{R}\left(t_{i} \rightarrow \infty\right)\right) \\
C_{R}\left(t_{i} \rightarrow \infty\right)=\mathrm{c}_{r} \cdot L_{R}\left(t_{i} \rightarrow \infty\right)
\end{gathered}
$$

$$
C_{F}\left(t_{i} \rightarrow \infty\right)=\mathrm{c}_{f} \cdot L_{F}\left(t_{i} \rightarrow \infty\right)
$$

Thus, the long-term expected maintenance costs per unit time $C\left(t_{i} \rightarrow \infty\right)$ may be defined according to the well know formulae:

$$
C\left(t_{i} \rightarrow \infty\right)=\frac{C_{I}\left(t_{i} \rightarrow \infty\right)+C_{R}\left(t_{i} \rightarrow \infty\right)+C_{F}\left(t_{i} \rightarrow \infty\right)}{T_{M}\left(t_{i} \rightarrow \infty\right)}
$$

\subsection{The convergence of analytical and simulation results of the presented maintenance model}

In order to present the convergence of the foregoing models and simulation ones, presented in the literature (see e.g. [18]), in this Subsection authors focus on the comparison of the obtained results for general case, taking into account the technical object exemplary parameters.

The Figure 6 shows the total expected length of the object up time in the curse of a single renew cycle (TM) calculated analytically by equation (10), and using a Monte Carlo simulation. As it can be seen, the results are characterized by a very large convergence, and the maximum relative error for the presented case is $4 \%$ of the "simulation cycle length". Other obtained results are characterized by a similar convergence, regardless of the given parameters of the object.

In addition to comparing the results, the Figure 6 shows that the two test parameters $T$ and $h$ have a significant impact on the length of the object lifetime. Shorter time intervals between inspection actions performance (shorter $T$ ) mean that the occurred defects in the object are more often identified during inspection. This also affects the length of the object operating time by preventive replacement performance (lower values of TM).

Change of the parameter $h$ in the analysed case means the change of time $u$, after which a defect occurs in the item. It was assumed, that the tested objects are characterized by the same expected operational time $(h+u=100=$ constant $)$ and there are changed only the lengths of each "sub-period" $u$ and $h$. Increasing value of $h$ means that the signal of impending failure can be observed earlier and for a longer period than in the case of decreasing $h$. In the examined case, the maximum value of $h(h=90)$ indicates that the defect signal is observable in the object for about 9 of 10 parts of its time to failure. In the Figure 6, it can be seen that in this case frequent object inspections reduce several times the potential object operational time in the system through preventive replacement performance. Such an undesirable effect can be seen in the Figure 7, which shows the availability ratio for the same random variable of $T$ and $h$. Frequent inspections in combination with the long-time of defect presence, cause a decrease in the object's availability for even adopted simplifying assumption of the equality of all time components $\left(d_{i}=d_{r}=d_{f}=1\right)$.

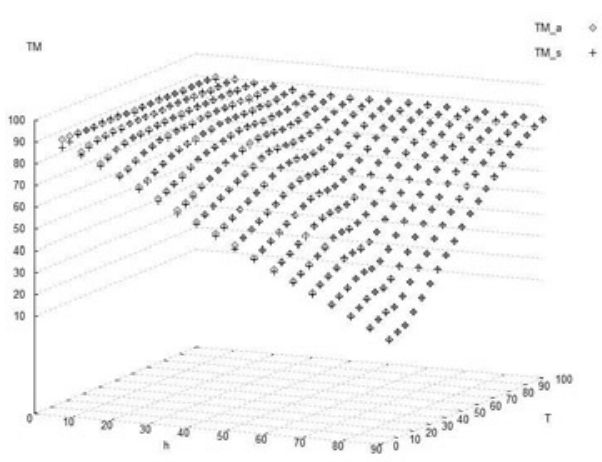

Fig. 6. The analytical (TM_a) and simulation-based (TM_s) expected lifetime of an element for various values of expected delay time ( $h$ ) and various lengths of times between inspections $(T)$ 


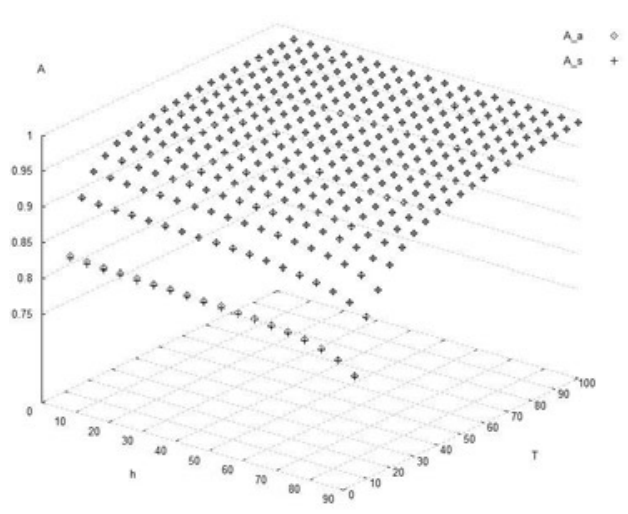

Fig. 7. The analytical (A_a) and simulation-based (A_s) system availability ratio for various values of expected delay time ( $h$ ) and various lengths of times between inspections (T)

These results illustrate how huge is the need for determining the time between inspection actions performance of the object for its main characteristics, as system reliability features, time components, or cost elements (Fig. 7). For this reason, in the next Section, there is presented a brief sensitivity analysis of the results obtained on the basis of the developed maintenance models.

\section{Sensitivity analysis of the developed availability and cost models for a single-unit system with delay- time}

In this Section, there is presented the short sensitivity analysis of the models developed above. The objective of the given analysis was to investigate what is the influence of given model basic time components on the object availability ratio level and maintenance costs in the infinite time horizon.

The sensitivity analysis of the developed cost and availability modes is begun by analysing the expected number of performed maintenance actions (failures (equation (8), preventive replacements (equation (7), and inspection actions (equation (3)), for various values of expected delay time $(h)$ and various lengths of times between inspections $(T)$ - Figures 8-10.

As we can see in the Figures 8-10, the expected number of performed inspection actions (Fig. 8) is inversely proportional to the rate of failure of the object due to the fact that only in the event of the object failure the renewal cycle does not end by inspection action performance. When the time of a defect occurrence is short $(h \approx 5-15)$, frequent inspections $(T \approx 5-10)$ cause that there is a necessity to perform them many times in a single renewal cycle (Fig. 8). On the other

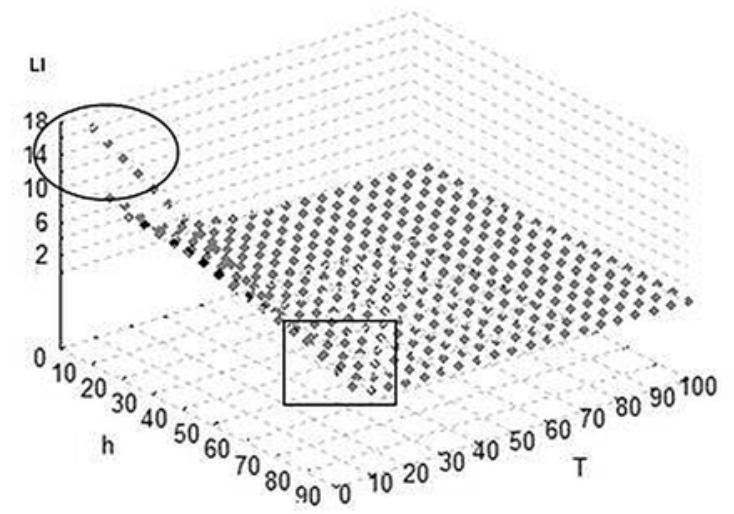

Fig. 8. The expected number of performed inspection actions (regardless of the result) in the single renew cycle for various values of expected delay time (h) and various lengths of times between inspections ( $T$ )

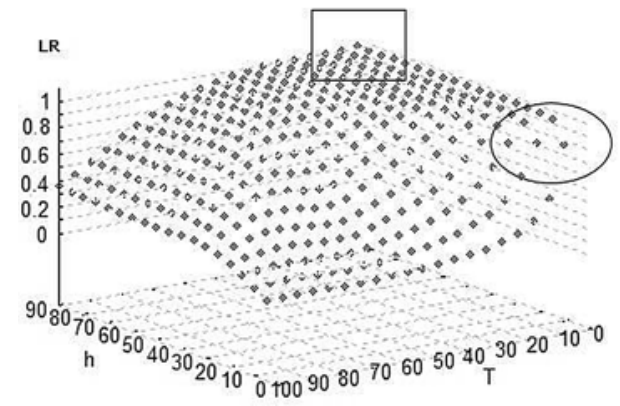

Fig. 9. The expected number of system's element preventive replacements in the single renew cycle for various values of expected delay time (h) and various lengths of times between inspections $(T)$

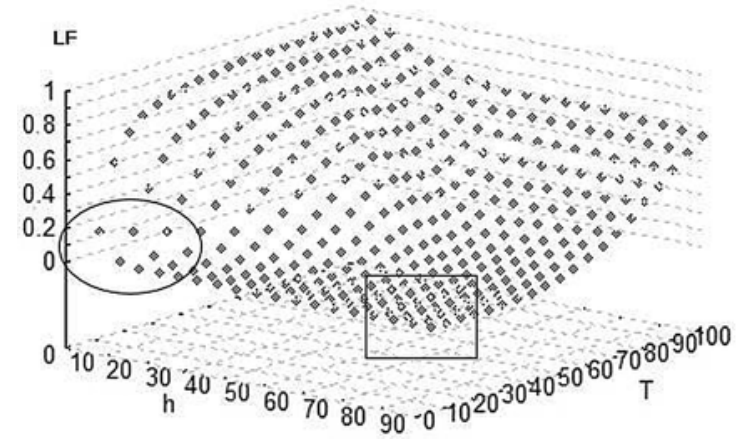

Fig. 10. The expected number of system's element corrective replacements in the single renew cycle for various values of expected delay time $(h)$ and various lengths of times between inspections $(T)$

hand, a large number of inspections results in higher effectiveness of inspection activities, as it significantly reduces the likelihood of object failure occurrence (Fig. 10). These cases are marked in the graphs by ellipses. However, the same time period between inspections $T$, used in the case of the objects with a long delay time ( $h \approx 50-90)$, does not significantly alter the probability of object failure, which remains low even in fewer inspections performance $(T \approx 20-30)$, but increases significantly the number of object preventive replacements (Fig. 9), which is indicated in the graphs by a rectangle.

As we can see in the Figures, for the tested values of $T$ and $h$ the expected numbers of inspections actions performance, preventive replacements and object failures have a large area of variation, which means that they are sensitive to both analysed parameters. While we are mostly not able to control the length of the object delay time $(h)$, it is possible to control the length of time between inspections actions performance $T$ in a system. However, the user has to answer the question of what criteria should and can be taken into account when optimizing time period $T$. Thus, the selected results on cost and reliability, achieved through the test object are presented in the Figures 11-14.

Graphs, presented in the Figures 11-14, show the object maintenance costs and its availability for the two chosen cases, where the unit inspection cost of an object and inspection time $\left(c_{i}, d_{i}\right)$ are relatively important compared with the preventive and corrective replacement times and costs (Figs. 11, 12), or where these parameters are of a little importance compared to the inspection and failure costs (Figs. $13,14)$. There can be seen in all of these Figures, that for any length of delay time $h$ there is a value of the period $T$, which gives better modelling results than for other lengths of $T$ (in Figures these values are marked by arc for the tested range of parameter $h$ ). A thorough analysis of the results confirms that the best $T$ period from the point of view of minimizing the object maintenance costs is close to the half of the delay time $h$ length. The relationship is similar to the Shannon rule that regards to continuous-time signals sampling. In the case of the objects inspection action performance, if the test procedure will 
be carried out at least twice in the expected delay time period, the chance to avoid costly failure to the object is the largest, and the costs are the smallest.

In the case of the availability ratio maximization, the best times between inspections $(T)$ stronger depend on the time units associated with each event in the object than it is observable for the cost minimization. When the single inspection action performance time $\left(d_{i}\right)$ is relatively small compared to the time of failure $\left(d_{r}\right)$ (Fig. 14), the solution that maximizes the availability of the object is achieved with more frequent inspections than in solutions optimizing the costs of the object maintenance (Fig. 13) for the same ratio of costs and time units.

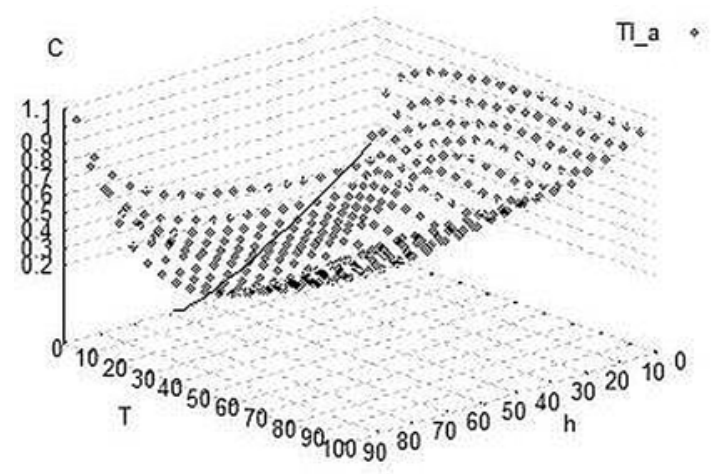

Fig. 11. The system expected maintenance costs for various values of expected delay time ( $h$ ) and various lengths of times between inspections $(T)$, assuming: $c_{i}=1, c_{r}=10, c_{f}=100$

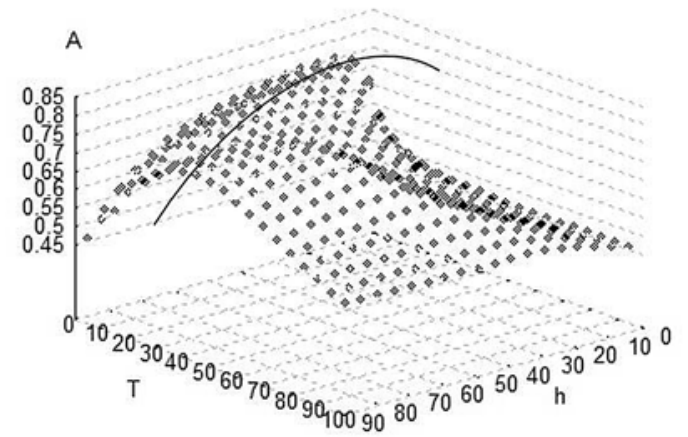

Fig. 12. The system availability ratio for various values of expected delay time (h) and various lengths of times between inspections (T), assuming: $d_{i}=1, d_{r}=10, d_{f}=100$

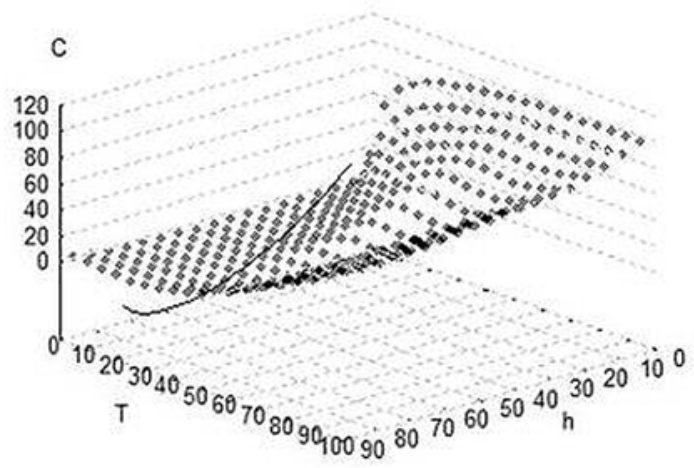

Fig. 13. The system expected maintenance costs for various values of expected delay time ( $h$ ) and various lengths of times between inspections $(T)$, assuming: $c_{i}=1, c_{r}=100, c_{f}=1000$

The presented examples show that the best time between inspections of the object must be determined individually for each change of reliability, cost, or time parameters and taking into account the

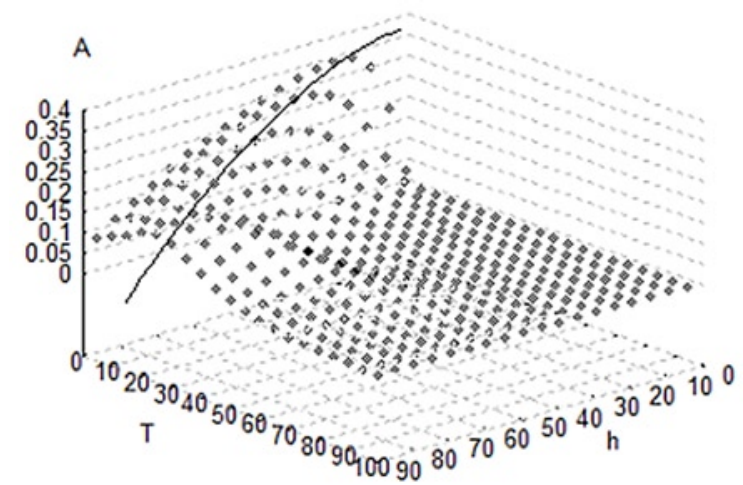

Fig. 14. The system availability ratio for various values of expected delay time (h) and various lengths of times between inspections (T), assuming: $d_{i}=1, d_{r}=100, d_{f}=1000$

chosen optimization criterion. Only in some cases, it may happen that the same period $T$ will give the best results in terms of both the analysed criteria.

\section{Summary}

The paper presents analytical models describing the availability and maintenance costs of the technical object based on delay-time approach use. These models may be used to optimize the length of time between successive inspection actions performance $T$ for the given cost and reliability characteristics.

Presented in the literature known analytical maintenance models that base on the delay-time analysis implementation usually are limited to an analysis of the time period, from the moment of system's new element ("as good as new") launching to the moment of the first inspection action performance. The models proposed in this article provide the basis for analytical identification of the optimal length of time $T$ in the infinitely long time horizon of the technical object operation and maintenance. The paper also presents a brief sensitivity analysis of the obtained models for the selected object parameters, which led to the conclusion that the best lengths of time $T$, taking into account the maximization of the object availability, are not always equal to the best lengths of this time period being obtained from the point of view of obtaining the minimal maintenance costs of the given object. At the same time, the conducted research shows that for the various parameters of the object, there is only one global minimum of the cost function or maximum of its availability. Thus, this gives a possibility to search for the optimal time period $T$ with the use of widely known optimization methods, like anti-gradient methods of optimizing functions of one variable. This is a significant convenience compared to optimization solutions that based on simulation models.

The practical application of the presented model may be difficult, especially because of the assumption of perfect inspection case investigation. This is often seen in practice that the inspection action performance may not give the right answer if and what defect occurs in the system. This may be caused by various factors such as the skill of the inspector, the accuracy of the inspection tools, etc. Moreover, the maintenance decision may have a multidimensional nature and depend on the problems connected with definition if and what kind of signal of forthcoming failure may occur. Such a situation may lead to different decisions made by managers for the same maintenance situation. Thus, this issue will be the topic of authors' future papers. 


\section{References}

1. Attia A. F. Estimation of the reliability function using the delay-time models. Microelectronics Reliability 1997; 37(2): 323-327, https://doi. org/10.1016/S0026-2714(96)00012-1.

2. Babiarz B. An introduction to the assessment of reliability of the heat supply systems. International Journal of Pressure Vessels and Piping 2006; 83(4): 230-235, https://doi.org/10.1016/j.ijpvp.2006.02.002.

3. Bajda A., Wrażeń M., Laskowski D. Diagnostics the quality of data transfer in the management of crisis situation. Electrical Review 2011; 87(9A): 72-78.

4. Baker R. D., Wang W. Estimating the delay-time distribution of faults in repairable machinery from failure data. IMA Journal of Mathematics Applied in Business \& Industry 1992; 3: 259-281.

5. Cavalcante C. A. V., Scarf P. A., de Almeida A. T. A study of a two-phase inspection policy for a preparedness system with a defective state and heterogeneous lifetime. Reliability Engineering and System Safety 2011; 96: 627-635, https://doi.org/10.1016/j.ress.2010.12.004.

6. Cerone P. On a simplified delay time model of reliability of equipment subject to inspection monitoring. Journal of the Operational Research Society 1991; 42(6): 505-511, https://doi.org/10.1057/jors.1991.98.

7. Christer A. H. A Review of Delay Time Analysis for Modelling Plant Maintenance. in: Stochastic Models in Reliability and Maintenance, Osaki S. (ed.), Springer, 2002, https://doi.org/10.1007/978-3-540-24808-8_4.

8. Christer A H. Developments in delay time analysis for modelling plant maintenance. Journal of the Operational Research Society 1999; 50: 1120-1137, https://doi.org/10.1057/palgrave.jors.2600837.

9. Christer A. H. Delay-time model of reliability of equipment subject to inspection monitoring. Journal of the Operational Research Society 1987; 38(4): 329-334, https://doi.org/10.1057/jors.1987.54.

10. Christer A. H. Modelling inspection policies for building maintenance. Journal of the Operational Research Society 1982; 33: 723-732, https://doi.org/10.1057/jors.1982.161.

11. Christer A. H., Waller W. M. A Descriptive model of capital plant replacement. Journal of the Operational Research Society 1987; 8(6): 473477, https://doi.org/10.2307/2582760.

12. Christer A. H., Waller W. M. Reducing production downtime using delay-time analysis. Journal of the Operational Research Society 1984; 35(6): 499-512, https://doi.org/10.1057/jors.1984.103.

13. Christer A. H., Waller W. M. Delay Time Models of Industrial Inspection Maintenance Problems. Journal of the Operational Research Society 1984; 35(5): 401-406, https://doi.org/10.1057/jors.1984.80.

14. Christer A. H., Wang W. A model of condition monitoring of a production plant. International Journal of Production Research 1992; 30(9): 2199-2211, https://doi.org/10.1080/00207549208948145.

15. Christer A.H., Wang W., Choi K., Van der Duyn Schouten F. A. The robustness of the semi-Markov and delay time single-component inspection models to the Markov assumption. IMA Journal of Management Mathematics 2001; 12: 75-88, https://oi.org/10.1093/imaman/12.1.75.

16. Dekker R., Scarf P. A. On the impact of optimisation models in maintenance decision making: the state of the art. Reliability Engineering and Safety 1998; 60: 111-119, https://doi.org/10.1016/S0951-8320(98)83004-4.

17. Frostig E. Comparison of maintenance policies with monotone failure rate distributions. Applied Stochastic Models in Business and Industry 2003; 19: 51-65, https://doi.org/10.1002/asmb.485.

18. Jodejko-Pietruczuk A., Nowakowski T., Werbińska-Wojciechowska S. Time between inspections optimization for technical object with time delay. Journal of Polish Safety and Reliability Association, Summer Safety and Reliability Seminars 2013; 4(1): 35-41.

19. Jia X. Christer A. H. A periodic testing model for a preparedness system with a defective state. IMA Journal of Management Mathematics 2002; 13: 39-49, https://doi.org/10.1093/imaman/13.1.39.

20. Jiang R. A timeliness-based optimal inspection interval associated with the delay time model. Proc. of Prognostic and System Health Management Conference PHM - 2012, Beijing, 2012, https://doi.org/10.1109/phm.2012.6228965.

21. Kierzkowski A., Kisiel T. Functional readiness of the check-in desk system at an airport. Theory and engineering of complex systems and dependability. Proc. of the Tenth International Conference on Dependability and Complex Systems DepCoS-RELCOMEX, June 29 - July 3 , 2015, Brunów, Poland. Springer, 2015;. 223-233, https://doi.org/10.1007/978-3-319-19216-1_21.

22. Laskowski D., Bylak M. Efficient diagnostics encoding mechanism for wireless networks. Electrical Review 2013; 89(9): 133-138.

23. Mazzuchi T. A., van Noortwijk J. M., Kallen M. J. Maintenance optimization. Technical Report, TR-2007-9, 2007.

24. Okumura S. An Inspection Policy for Deteriorating Processes Using Delay-Time Concept. International Transactions in Operational Research 1997; 4(5-6): 365-375, https://doi.org/10.1111/j.1475-3995.1997.tb00092.x.

25. Okumura S., Jardine A. K. S., Yamashina H. An inspection policy for a deteriorating single-unit system characterized by a delay-time model. International Journal of Production Research 1996; 34(9): 2441-2460, https://doi.org/10.1080/00207549608905037.

26. Ozekici S. (ed.). Reliability and Maintenance of Complex Systems. NATO ASI Series, Series F: Computer and Systems Sciences, 154. Springer, 1996.

27. Redmond D. F. Delay Time Analysis in Maintenance. PhD thesis. Salford: University of Salford; 1997.

28. Restel F.J. The Markov reliability and safety model of the railway transportation system. Safety and reliability: methodology and applications: proceedings of the European Safety and Reliability Conference, ESREL 2014, 14-18 September, 2015, Wrocław, Poland. CRC Press/ Balkema: 303-311.

29. Tang Y., Jing J. J., Yang Y., Xie C. Parameter estimation of a delay time model of wearing parts based on objective data. Mathematical Problems in Engineering 2015, https://doi.org/10.1155/2015/419280.

30. Valdez-Flores C., Feldman R. A survey of preventive maintenance models for stochastically deteriorating single-unit systems. Naval Research Logistics 1989; 36: 419-446, https://doi.org/10.1002/1520-6750(198908)36:4<419::AID-NAV3220360407>3.0.CO; 2-5.

31. Valis D., Koucky M., Žak L. On approaches for non-direct determination of system deterioration. Eksploatacja i Niezawodnosc - Maintenance and Reliability 2012; 14(1): 33-41.

32. Valis D., Vintr Z. Vehicle Maintenance Process Optimisation Using Life Cycle Costs Data and Reliability-Centred Maintenance. Proceedings of the First International Conference on Maintenance Engineering. Beijing: Science Press, 2006. 
33. Van Oosterom C. D., Elwany A. H., Celebi D., van Houlum G. J. Optimal policies for a delay time model with postponed replacement. European Journal of Operational Research 2014; 232: 186-197, https://doi.org/10.1016/j.ejor.2013.06.038.

34. Vintr Z., Valis D. A Tool for Decision Making in k-out-of-n System Maintenance. Applied Mechanics and Materials 2012; 110-116: 52575264.

35. Wang H. A survey of maintenance policies of deteriorating systems. European Journal of Operational Research 2002; 139: 469-489, https:// doi.org/10.1016/S0377-2217(01)00197-7.

36. Wang W. An overview of the recent advances in delay-time-based maintenance modelling. Reliability Engineering and System Safety 2012; 106: 165-178, https://doi.org/10.1016/j.ress.2012.04.004.

37. Wang W. Delay time modelling. In: Kobbacy K. A. H., Prabhakar Murphy D. N. (eds.). Complex system maintenance handbook. SpringerVerlag London Limited, 2008: 345-373, https://doi.org/10.1007/978-1-84800-011-7_14.

38. Wang W. A delay time based approach for risk analysis of maintenance activities. Journal of the Safety and Reliability Society 2003; 23(1):103-113, https://doi.org/10.1080/09617353.2002.11690753.

39. Wang W., Christer A. H. A modelling procedure to optimize component safety inspection over a finite time horizon. International Quality and Reliability Engineering 1997; 13: 217-224. https://doi.org/10.1002/(SICI)1099-1638(199707)13:4<217::AID-QRE107>3.0.CO;2-P

40. Yamashina H., Otani S. Cost-optimized maintenance of the elevator - single unit case. Journal of Quality in Maintenance Engineering 2001; 7(1): 49-70. https://doi.org/10.1108/13552510110386946

41. Zajac M., Swieboda J. Process hazard analysis of the selected process in intermodal transport. International Conference on Military Technologies (ICMT), 19-21 May 2015; 1-7. https://doi.org/10.1109/miltechs.2015.7153698

42. Zieja M., Wazny M., Stepien S. Distribution determination of time of exceeding permissible condition as used to determine lifetimes of selected aeronautical devices/systems. Eksploatacja i Niezawodnosc - Maintenance and Reliability 2016; 18(1): 57-64. https://doi. org/10.17531/ein.2016.1.8

43. Zhao J., Chan A. H. C., Roberts C., Madelin K. B. Reliability evaluation and optimisation of imperfect inspections for a component with multi-defects. Reliability Engineering and System Safety 2007; 92: 65-73. https://doi.org/10.1016/j.ress.2005.11.003

\section{Anna JODEJKO-PIETRUCZUK Sylwia WERBIŃSKA-WOJCIECHOWSKA}

Faculty of Mechanical Engineering

Department of Operation and Maintenance of Logistic Systems,

Transportation Systems and Hydraulic Systems

Wroclaw University of Science and Technology

ul. Wybrzeze Wyspianskiego 27, 50-370, Wroclaw, Poland

E-mails: anna.jodejko@pwr.edu.pl, sylwia.werbinska@pwr.edu.pl 